\title{
Prevalence of delirium in intensive care patients and association with sedoanalgesia, severity and mortality
}

\author{
Prevalência de delirium em pacientes de terapia intensiva e \\ associação com sedoanalgesia, gravidade e mortalidade \\ Prevalencia de delirio en pacientes de cuidados intensivos y \\ asociación con la sedoanalgesia, gravedad y mortalidad
}

\section{Alessandra Soler Bastos $^{\mathrm{a}}$ Lúcia Marinilza Beccaria ${ }^{a}$ Daniele Cristiny da Silva ${ }^{a}$ Taís Pagliuco Barbosaa ${ }^{a}$}

How to cite this article: Bastos AS, Beccaria LM, Silva DC, Barbosa TP. Prevalence of delirium in patients at intensive care and association with sedoanalgesia, gravity and mortality. Rev Gaúcha Enferm. 2020;41:e20190068. doi: https://doi.org/10.1590/19831447.2020.20190068
Faculdade de Medicina de São José do Rio Preto (FAMERP). São José do Rio Preto, São Paulo, Brasil.

\section{ABSTRACT}

Objective: To establish the prevalence of delirium and its subsyndrome in intensive care and to associate it with the use of sedative and analgesia, severity and mortality.

Method: Carried out in two intensive care units of adult patients, this is a quantitative and transversal study, with 157 patients, using the Richmond Agitation-Sedation Scale to assess the level of sedation and the Intensive Care Delirium Screening Checklist for delirium. The T test and Chi-square test were applied for statistical analysis.

Results: The prevalence of delirium was $22.3 \%$, and $49.7 \%$ of the subsyndrome. Associations of the use of midazolam with the presence of delirium $(p=0.05)$ and subsyndromal delirium $(p<0.01)$, use of clonidine with the appearance of delirium $(p<0.01)$ and of fentanyl with subsyndromal delirium $(p=0.09)$. There were no significant differences between the mortality of patients with delirium ( $p=0.40$ ) and subsyndromal delirium ( $p=0.86)$, as well as association with the mortality score.

Conclusion: The use of sedoanalgesia is associated with the presence of delirium and subsyndromal delirium. No significant statistical associations were found between the severity and mortality scores.

Keywords: Hypnotics and sedatives. Delirium. Intensive care units. Nursing care.

\section{RESUMO}

Objetivo: Estabelecer a prevalência do delirium e sua subsíndrome em pacientes de terapia intensiva e associar com uso de sedoanalgesia, gravidade e mortalidade.

Método: Realizado em duas Unidades de Terapia Intensiva de pacientes adultos, trata-se de estudo quantitativo e transversal, com 157 pacientes, utilizando as escalas Richmond Agitation-Sedation Scale para avaliação do nível de sedação e Intensive Care Delirium Screening Checklist para delirium. Foi aplicado o teste te qui-quadrado para análise estatística.

Resultados: A prevalência de delirium foi 22,3\% e da subsíndrome 49,7\%. Foram encontradas associações do uso de midazolan com a presença de delirium $(p=0,05)$ e delirium subsindromático $(p<0,01)$, uso de clonidina com 0 aparecimento de delirium $(p<0,01)$ e de fentanil com o delirium subsindromático $(p=0,09)$. Não houve diferenças significativas entre mortalidade de paciente com delirium $(p=0,40)$ e delirium subsindromático ( $p=0,86)$, bem como associação com o escore de mortalidade.

Conclusão: 0 uso de sedoanalgesia está associado à presenta de delirium e delirium subsindromático. Não foram encontradas associações estatísticas significativas entre os escores de gravidade e mortalidade.

Palavras-chave: Hipnóticos e sedativos. Delirium. Unidade de terapia intensiva. Cuidados de enfermagem.

\section{RESUMEN}

Objetivo: Establecer la prevalencia del delirio y su subsíndrome en pacientes de cuidados intensivos y asociarlos con el uso de la sedoanalgesia, con la gravedad y con la mortalidad.

Método: Realizado en dos unidades de cuidados intensivos de pacientes adultos, se trata de un estudio cuantitativo y transversal, con 157 pacientes, utilizando las escalas Richmond Agitation-Sedation Scale (Escala de agitación-sedación de Richmond) para evaluar el nivel de sedación y la de la Intensive Care Delirium Screening Checklist (Lista de verificación para la detección del delirio en cuidados intensivos) para el delirio. Se aplicaron las pruebas de Ty Chi-cuadrado para el análisis estadístico.

Resultados: La prevalencia del delirio fue del 22,3\%, y la del subsíndrome fue del 49,7\%. Se han encontrado asociaciones del uso de midazolan con la presencia de delirio $(p=0,05)$ y del deilirio subsindromático $(p<0,01)$, del uso de clonidina con la aparición de delirio $(p<0,01)$ y de fentanil con el delirio subsindromático $(p=0,09)$. No se registraron diferencias significativas entre la mortalidad de los pacientes con delirio $(p=0,40)$ y el delirio.

Conclusión: El uso de sedoanalgesia se asocia con la presencia de delirio y delirio subsindromático. No se encontraron asociaciones estadísticas significativas entre la gravedad y las puntuaciones de mortalidad.

Palabras clave: Hipnóticos y sedantes. Delirio. Unidades de cuidados intensivos. Atención de enfermería. 


\section{口INTRODUCTION}

Delirium is understood as a confusional state arising from a potentially reversible acute brain dysfunction that can be detected upon admission to the hospital or may arise during admission and persist after discharge. It occurs due to clinical or surgical conditions of the patient, the action of medications, exposure to toxins or a combination of all factors. It is characterized by a cognitive decline in the level of awareness and attention, behavioral and mood changes, increased or decreased psychomotor activity, and altered sleep-wake cycle. Early recognition and prevention are the best ways to reduce and treat delirium ${ }^{(1-3)}$.

It is known that this disease increases ICU and hospital stay, mechanical ventilation time, mortality, that it interferes with the assessment and management of pain and other symptoms, increases hospital costs, decreases functionality and quality of life after hospital discharge and has negative impact on patients, family members and health professionals. Therefore, there is a need to quickly identify and act assertively to improve the prognosis and quality of life of the patient $t^{(1,4-6)}$.

Delirium is one of the factors that causes most agitation in critically ill patients, increasing the risk of self-extubation, device removal, falls and injury. Thus, nurses should plan nursing care individually and specifically, using delirium diagnostic scales, and develop institutional protocols that promote the identification of its signs in order to improve care for critically ill patients (1-2,4,7). $^{(1)}$

The guidelines advocated by the Diagnostic and Statistical Manual of Mental Disorders, (DSM-V) or the International Classification of Disease, $10^{\text {th }}$ revision (ICD-10) are the gold standard for delirium diagnosis, but require specific knowledge of neuroscience, apart from longer time for evaluation, which hinders its routine use. This way, scales were created to enable fast and effective diagnosis in critically ill patients, such as the Intensive Care Delirium Screening Checklist (ICDSC) ${ }^{(8-9)}$.

The ICDSC was established in 2001, based on the DSM-V criteria and is a checklist consisting of eight assessment items. With this scale it is possible to score the number of delirium signs and to classify patients with subsyndromal delirium (SSD), which is the presence of only some symptoms. On this scale, a score from 1 to 3 is a subsyndrome and scores of 4 or more items, delirium. This survey is extremely important because if it is detected and the symptoms are treated early, it prevents the patient from developing delirium ${ }^{(1-2,8,10-11)}$.

The pathophysiology of delirium is complex, but its etiology is known as a number of comorbidities and triggering risk factors such as invasive mechanical ventilation, cerebral hypoxia, psychoactive drug use, severe sepsis and neglected pain. Due to the continuous exposure to these risk factors, the critically ill patient is likely to develop this syndrome. Thus, the identification of the triggering factors is necessary, since about $50 \%$ of delirium cases are potentially reversible ${ }^{(5,7,12)}$.

Currently, the most accepted theory of delirium pathophysiology is that the the cause such symptoms is the decrease in the cholinergic activity associated with dopaminergic increase, corroborated by the lack of attention caused by anticholinergic medications. From a neuroscience perspective, delirium is believed to be related to imbalance in the synthesis, release and inactivation of neurotransmitters, modulating the control of the cognitive function, behavior and $\operatorname{mood}^{(5,13)}$.

Delirium has long been considered a risk factor for mortality in the ICU and after hospital discharge, causing greater patient dependence and long-term cognitive impairment. Hospital mortality in patients with delirium ranges from 25\% to $33 \%$, but the statistical association is less clear ${ }^{(5-6,12-13)}$.

Delirium SSD is associated with the same risk factors as delirium. Although it has been shown to be associated with longer ICU and hospital stay, these outcomes are less conclusive and need further study. Based on works in recent years, approximately $25 \%$ of the patients diagnosed with delirium SSD using ICDSC on admission have progressed to evident delirium due to lack of treatment, but few studies have shown the mortality of these patients and their association with severity $(4,7,10-11)$.

The treatment for delirium is non-pharmacological, through early patient mobilization, staying with family members, preservation of the sleep-wake cycle, time-space reorientation, and visual aids that aid orientation such as clocks, calendars, personal and other familiar elements. However, there are situations in which these treatments are not enough, and patients get agitated and uncomfortable, requiring pharmacological intervention. For this, non-benzodiazepine sedatives such as propofol, dexmedetomidine and clonidine, or antipsychotics such as haloperidol and quetiapine are used, but the latter still have scarce scientific evidence to reduce the onset of delirium ${ }^{(1,4-6,13)}$.

In order to provide comfort, reduce stress and anxiety of mechanically ventilated patients, sedatives are used for well-informed purposes and for a limited time, as the Society of Critical Care Medicine (SCCM) recommends its use in a moderate manner and daily assessment as part of the care for critically ill patients. Thus, nurses should have a broad knowledge of the pharmacology of these sedatives and balance the administration of these drugs, maintaining light sedation and providing comfort to the patient $(4,6,6,14)$.

The ICU's hostile environment is a risk factor for delirium and the indiscriminate use of sedation may contribute to its onset, thus, the aim of this study was to establish the 
prevalence of delirium and subsyndromal delirium in intensive care patients and to identify the association with the use of sedoanalgesia, with severity and with mortality.

\section{METHOD}

A descriptive, quantitative, cross-sectional study, carried out at the Hospital de Base de São José do Rio Preto, a teaching hospital, in two ICUs of adult patients (Neurological and General), totaling 27 beds, which serves the Unified Health System (Sistema Único de Saúde, SUS). Data collection took place from January 2015 to January 2016.

The first phase involved 240 patients, evaluated by the nurse team for sedation level, through the Richmond Agitation-Sedation Scale (RASS). This scale is based on a score ranging from -5 to +4 . The number zero refers to the alert patient without apparent agitation or sedation; levels below zero mean that the patient has some degree of sedation and higher than zero mean some degree of agitation ${ }^{(1,13)}$.

In the second phase, patients with a RASS value between -2 and +4 were selected, so that delirium could be evaluated by the ICDSC. This scale was chosen because it is easy to apply and can be used by doctors and nurses, the application time ranges between one and two minutes and can be used in patients with communication difficulties, especially those with mechanical ventilation, and also for its ability to identify delirium and subsyndromal delirium ${ }^{(8-9)}$.

The ICDSC scale is a checklist for the diagnosis of delirium, consisting of eight items related to: awareness, attention, disorientation, hallucinations or psychosis, psychomotor retardation or agitation, inappropriate mood or speech, sleep disturbance, and fluctuation of symptoms. Ranging from zero to eight, delirium is considered to have a score greater than or equal to four, and subsyndromal delirium has a score between one and three ${ }^{(8-11)}$.

Of a population of 240 patients, 83 were excluded for not meeting the inclusion criteria, which were ICU admission for at least 24 hours and mild sedation (RASS $\geq-2$ ), totaling a sample of 157. Data collection on age, gender, medical specialty, length of stay, ICU outcome (hospital discharge or death), and outcome after ICU discharge were obtained from the electronic medical record.

Regarding the score for predicting severity, the Sepsis-Related Organ Failure Assessment (SOFA) was used, which is an instrument that describes the degree of organ dysfunction during a patient's ICU stay. It is obtained by scoring variables regarding the patient such as: vasoactive drug use, platelet count, Glasgow coma scale, among other( ${ }^{(15)}$. The instrument was applied daily by intensive care physicians and stored in the patient's electronic medical record, from which data were obtained for severity analysis. The mean value between the SOFA values and the ICU stay days was verified for statistical analysis.

For sedation and delirium monitoring, previously all nurses from the units under study received specific training on the completion of the scales and their clinical importance. After training, the scales were incorporated into the ICU routine. The scales were completed by the nurses of the unit from Monday to Friday on all shifts (morning, afternoon and night), observing the patient at bedside and filling all items of the instrument.

The analyses of the sample characterization variables were described in absolute and percentage numbers, and the quantitative ones were expressed as mean value and standard deviation. The t-test for independent samples was applied in order to compare the delirium symptoms with the mean SOFA score, and the patient with the highest mean score was considered to be more severe. The chisquare test was applied to observe associations among delirium and the variables: the use of sedoanalgesia and different types of medications, discharge and death from the ICU and hospital. Significant results were considered when $p<0.05$. The study complied with Resolution 466/12. The project was approved by the Ethics Committee of the School of Medicine of São José do Rio Preto, under Opinion No.984,505.

\section{a RESULTS}

Of the 157 patients evaluated, most were male (65\%), with aa mean age of 53.2 years old. At ICU admission, 47\% had neurosurgery-related diagnoses such as polytrauma (23), traumatic brain injury (19), intracranial tumors (16), hemorrhagic cerebrovascular accident (16) and ischemic stroke (5), followed by hospitalization for diseases related to orthopedics (21.8\%), general surgery (13.5\%) and cardiovascular surgery (6.4\%), among others. There were no significant differences between the diagnosis of hospitalization and the delirium symptoms.

The prevalence of delirium was $22.3 \%$, and of subsyndromal delirium, $49.7 \%$. The association with the use of sedoanalgesia was significant for delirium $(p=<0.01)$ and for subsyndromal delirium ( $p=0.01$ ) (Table 1).

The most commonly used sedoanalgesia was fentanyl (43.3\%), followed by midazolam (36.9\%), propofol (14\%) and clonidine (12.7\%). Associations were found between the drug midazolam and the presence of delirium and subsyndromal delirium ( $p=0.05$ and $p<0.01)$, clonidine with delirium $(p<0.01)$ and fentanyl with subsyndromal delirium $(p=0.09)$ (Table 2). 
The mean value found of the SOFA predictor mortality score for the patients evaluated was 4.54 with a median of 4.59 and a maximum of 24. No associations were found between the mortality score and the presence of delirium and subsyndromal delirium (Table 3).

The overall mortality rate in the ICU was $21.7 \%$ (34) and in the hospital, $11.4 \%$ (14). Of the patients who died in the ICU, 29.1\% (10) had delirium and 44.1\% (15) delirium SSD. Already those who died in the hospital, 14.3\% (2) had delirium and 50\% (7) SSD. When ICU mortality was associated, no significant differences were found either for patients with delirium ( $p=0.40)$ or with delirium SSD ( $p=0.86)$.

In the hospital, for patients who were discharged from the ICU and presented symptoms of delirium, no significant association was found between the mortality rate of delirium ( $p=0.38$ ) and delirium SSD ( $p=0.67)$, showing that delirium was not a predictor of mortality either in the ICU or in inpatient units.

Table 1 - Comparison of the patients who used sedoanalgesia or not, with the patients diagnosed with delirium and subsyndromal delirium - São José do Rio Preto - Brazil - 2016

\begin{tabular}{lccc} 
& \multicolumn{2}{c}{ Use of sedoanalgesia } & \\
\cline { 2 - 3 } Variables & $\mathbf{n}(\%)$ & $\mathbf{n}$ p-value* \\
\hline Delirium & $22(28.2)$ & $13(16.5)$ & $<0.01$ \\
\hline Subsyndromal Delirium & $42(53.8)$ & $36(45.5)$ & 0.01 \\
\hline Total & $78(49.7)$ & $79(50.3)$ & \\
\hline
\end{tabular}

Source: Research data, 2016

Note: * ${ }^{*}$ hi-square Test.

Table 2 - Comparison between the delirium and subsyndromal delirium variables and the days of sedoanalgesia used by the patient - São José do Rio Preto - Brazil - 2016

\begin{tabular}{llll} 
Variables & \multicolumn{1}{c}{ ICDSC } & Mean value \pm SD & p-value(1) \\
\hline Fentanyl & Delirium & $1.54 \pm 2.29$ & 0.12 \\
\cline { 2 - 4 } & Delirium SSD(2) & $2.57 \pm 4.21$ & 0.09 \\
\hline Midazolam & Delirium & $1.14 \pm 2.03$ & 0.05 \\
\cline { 2 - 4 } & Delirium SSD & $2.05 \pm 3.47$ & $<0.01$ \\
\hline Propofol & Delirium & $0.54 \pm 1.52$ & 0.47 \\
\cline { 2 - 4 } & Delirium SSD & $0.69 \pm 2.30$ & 0.24 \\
\hline Clonidina & Delirium & $0.74 \pm 1.09$ & $<0.01$ \\
\cline { 2 - 4 } & Delirium SSD & $0.16 \pm 0.63$ & 0.15 \\
\hline Others (3) & Delirium & $0.02 \pm 0.16$ & 0.75 \\
\cline { 2 - 4 } & Delirium SSD & $0.02 \pm 0.22$ & 0.70
\end{tabular}

Source: Research data, 2016.

Note: ICDSC: Intensive Care Delirium Screening Checklist. (1) Chi-square Test.

(2) Subsyndromal Delirium. (3) Others: dexmedetomidine, ketalar and thionembutal. 
Table 3 - Descriptive characteristics and comparison of the SOFA mortality score with the delirium and subsyndromal delirium variables - São José do Rio Preto - Brazil - 2016

\begin{tabular}{cccc} 
& Delirium & Delirium SSD & p-value \\
\cline { 2 - 3 } SOFA Score & $\mathbf{n}=\mathbf{3 5}$ & $\mathbf{n = 7 8}$ & \\
\hline $4.93 \pm 2.70$ & $4.40 \pm 2.71$ & 0.59 \\
\hline $5(3.3-5.6)$ & $4.6(2-6)$ & 0.93 \\
\hline
\end{tabular}

Source: Research data, 2016.

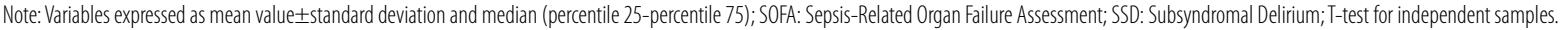

\section{DISCUSSION}

The analyses of this research show that delirium SSD was present in $49.7 \%$ of the population and delirium in $22.3 \%$. According to studies, in patients admitted to wards, the incidence of delirium ranges from $11 \%$ to $42 \%$, but it can reach $90 \%$ in the ICU. It was found, respectively, that $60 \%$ and $80 \%$ of the critically ill patients on spontaneous breathing and on mechanical ventilation were diagnosed with delirium. Similarly, 34\% and 54\%, respectively, were diagnosed with delirium SSD, data that corroborate this study ${ }^{(4-5,11,13,16-18)}$.

When comparing the delirium symptoms with the use of sedoanalgesia, it was found that the patients with delirium and delirium SSD used at least one sedoanalgesia during the ICU stay, and the association for both was statistically significant ( $p=0.01$ and $p<0.01$ ). The use of benzodiazepines is a risk factor for the development of delirium; if not stopped early, such practice causes a vicious cycle in which the sedative increases the symptoms of delirium, and in turn is treated with sedation abuse, thus increasing mechanical ventilation time, the length of stay in the ICU and in the hospital, increasing costs, hindering the correct assessment of pain and causing suffering for the patient and his family $(1-2,4,6,14,17,19)$.

In this study, the use of midazolam (benzodiazepine) was statistically associated with delirium, corroborating several studies and guidelines $(p=0.05)^{(6,17-18)}$. Clonidine, a classically antihypertensive a2-agonist, used for superficial ICU sedation also showed a significant association when compared to delirium $(p<0.01)$. This drug is used in the studied ICUs, especially after patient evaluation and identification of hyperactive delirium associated with hypertension, which may justify the association ${ }^{(3)}$.

SSD was only associated with the use of fentanyl in this study. This may be justified by the difficulty of pain assessment, especially in mechanically ventilated patients. Fentanyl infusions are then used to provide analgesia and anxiolysis and increase ventilator tolerance. There are few studies relating delirium SSD with fentanyl use, and an association with delirium alone has been demonstrated, which raises the need for further studies on this subject ${ }^{(17,19)}$.

To measure the severity of critically ill patients over the length of stay, SOFA is widely used because it is able to measure the degree of organic dysfunction. The mean SOFA value of the ICU analyzed was 4.54 points, and that found in the other studies range from 3 to 6 points, considered low risk of mortality. When comparing the SOFA of the patients with delirium and delirium SSD, no significance was found ( $p=0.59$ and 0.93 ). Most of the previous studies corroborate with this study, and some used other instruments to predict mortality, yet we can observe that the data related to severity is still scarce, especially in patients with delirium SSD. A study was recently published with 141 patients showing that the SOFA at admission in the ICU was statistically associated with the onset of delirium, corroborating the 2002 guideline on pain management, agitation and delirium ${ }^{(4,15,20)}$.

Delirium has long been considered a risk factor for mortality in the ICU and after hospital discharge, causing greater patient dependence and long-term cognitive impairment. Hospital mortality in patients with delirium ranges from $25 \%$ to $33 \%$, but the statistical association is less clear. In this study, the ICU mortality rate of delirium patients was $29.1 \%(p=0.40)$, within the range found in previous studies but, when the association was performed, delirium was not statistical significance with mortality. When relating the data with the other studies, both results were found, still being controversial. This fact may be related mainly to the different profiles and clinical characteristics of the evaluated patients. The concept that delirium is a strong risk factor for mortality is better accepted ${ }^{(5-6,12-13,18)}$.

The mortality rate of patients with delirium SSD in this study was $44.1 \%(p=0.86)$ and after discharge from the ICU, still in the hospital $50 \%(p=0.67)$. No associations were found of mortality with delirium SSD, which corroborates with previous studies, showing that the mortality of these patients 
is similar to the rates of those without delirium symptoms. However, in an international study of 610 patients, it was shown that we cannot disregard the mortality risk of these patients with delirium SSD, being characterized as intermediate risk by the authors ${ }^{(11,18)}$.

\section{- CONCLUSION}

Delirium symptoms are common in ICU patients and should be investigated as it is a problem that has no well-defined pharmacological treatment, influencing prognosis. This study provides new data for a better understanding of delirium and delirium SSD epidemiology, the influence of sedoanalgesia use and association with patient clinical severity and mortality.

The daily use of the RASS and ICDSC tools by ICU nurses allowed us to identify the sedation level and prevalence of delirium and delirium SSD of critically ill patients and to identify an association of sedoanalgesia with delirium and delirium SSD. The use of midazolam was associated with increased delirium and its subsyndrome, clonidine only with increased delirium and fentanyl only with increased delirium SSD.

No association was found between the mortality score (SOFA) and the presence of delirium and delirium SSD. The mortality rate of patients with delirium during ICU stay and after discharge, admitted to hospital units, was lower than those with subsyndromatic delirium. Despite the high rate of delirium and delirium SSD patients using sedoanalgesia, no statistical significant associations were found between severity and mortality scores.

\section{— LIMITATION OF THE STUDY}

The lack of information about psychiatric background, use of psychotropic medicine, alcohol consumption and use of drugs of the patients studied before ICU admission was one of the limitations of the study, as they are fundamental for statistical analysis. Another limitation is that the study was conducted in only one institution.

\section{REFERENCES}

1. Faria RSB, Moreno RP. Delirium in intensive care: an under-diagnosed reality. Rev Bras Ter Intensiva. 2013;25(2):137-47. doi: https://doi.org/10.5935/0103507X.20130025

2. Sena T. Manual diagnóstico e estatístico de transtornos mentais - DSM5, estatísticas e ciências humanas: inflexões sobre normalizações e normatizaçōes. Rev Inter Interdiscr INTERthesis. 2014;11(2):96-117. doi: https://doi.org/10.5007/1807-1384.2014v11n2p96
3. Berbigier EJ, Berbigier RJ, Moritz RD, Machado FR. Estudo comparativo da clonidina com a dexmedetomidina para a sedação do paciente crítico sob ventilação mecânica. Arq Catarin Med. 2014 [cited 2019 Feb 10];43(2):44-52. Available from: http://www.acm.org.br/revista/pdf/artigos/1286.pdf

4. Al-Qadheeb NS, Skrobik Y, Schumaker G, Pacheco M, Roberts R, Ruthazer $R$, et al. Preventing ICU subsyndromal delirium conversion to delirium with low dose IV haloperidol: a double-blind, placebo-controlled pilot study. Crit Care Med. 2016;44(3):583-91. doi: https://doi.org/10.1097/ CCM. 0000000000001411

5. Prayce R, Quaresma F, Glariça Neto I. Delirium: The 7th Vital Sign? Acta Med Port. 2018 Jan;31(1):51-8. doi: https://doi.org/10.20344/amp.9670

6. Barr J, Fraser GL, Puntillo K, Ely EW, Gélinas C, Dasta JF, et al. Clinical practice guidelines for the management of pain, agitation, and delirium in adult patients in the intensive care unit. Crit Care Med. 2013;41(1):263-306. doi: https://doi. org/10.1097/CCM.0b013e3182783b72

7. Souza RCS, Bersaneti MDR, Siqueira EMP, Meira L, Brumatti DL, Prado NRO. Nurses' training in the use of a delirium screening tool. Rev Gaúcha Enferm. 2017 mar;38(1):e64484. doi: https://doi.org/10.1590/19831447.2017.01.64484

8. Carvalho JPLM, Almeida ARP, Gusmão-Flores D. Escalas de avaliação de delirium em pacientes graves: revisão sistemática da literatura. Rev Bras Ter Intensiva. 2013;25(2):148-54. https://doi.org/10.5935/0103-507X.20130026

9. Flôres DG. Propriedades psicométricas de instrumentos diagnósticos para delirium no paciente grave em unidade de terapia intensiva [tese]. Salvador (BA): Federal University of Bahia. Instituto de Ciências da Saúde Salvador; 2013.

10. Hakim SM, Othman Al, Naoum DO. Early treatment with risperidone for subsyndromal delirium after on-pump cardiac surgery in the elderly. Anesthesiology 2012;116(5):987-97. doi: https://doi.org/10.1097/ALN.0b0 13e31825153cc

11. Serafim RB, Soares M, Bozza FA, Lapa e Silva JR, Dal-Pizzol F, Paulino MC, et al. Outcomes of subsyndromal delirium in ICU: a systematic review and metaanalysis. Crit Care. 2017;21(1):179. doi: https://doi.org/10.1186/s13054-0171765-3

12. Mesa P, Previgliano IJ, AltezS, Fravetto S, Orellano M, Lecor C, etal. Delirium in a Latin American intensive care unit. A prospective cohort study of mechanically ventilated patients. Rev Bras Ter Intensiva. 2017;29(3):337-45. doi: https://doi. org/10.5935/0103-507X.20170058

13. Luz LFS. Avaliação da associação do delirium com cognição, capacidade funcional e qualidade de vida em pacientes críticos [tese]. Canoas (RS): Centro Universitário La Salle; 2017.

14. Almeida TML, Azevedo LCP, Nosé PMG, Freitas FGR, Machado FR. Risk factors for agitation in critically ill patients. Rev Bras Ter Intensiva. 2016;28(4):413-9. doi: https://doi.org/10.5935/0103-507X.20160074

15. Hissa PNG, Hissa MRN, Araújo PSR. Análise comparativa entre dois escores na previsão de mortalidade em unidade terapia intensiva. Rev Bras Clin Med. 2013 [cited 2019 Jan 10];11(1):21-6. Available from: http://files.bvs.br/ upload/S/1679-1010/2013/N11n1/a3383.pdf

16. Pereira JM, Barradas FJR; Sequeira RMC, Marques MCMP, Batista MJ, Galhardas $\mathrm{M}$, et al. Delirium in critically ill patients: risk factors modiffable by nurses. Rev Enferm Referência. 2016;IV(9):29-36. doi: https://doi.org/10.12707/RIV16006

17. Mori S, Takeda JRT, Carrara FSA, Cohrs CR, Zanei SSV, Whitaker IY. Incidence and factors related to delirium in an intensive care unit. Rev Esc Enferm USP. 2016;50(4):587-93. doi: https://doi.org/10.1590/50080623420160000500007 
18. Diwell RA, Davis DH, VickerstaffV, Sampson EL. Key components of the delirium syndrome and mortality: greater impact of acute change and disorganised thinking in a prospective cohort study. BMC Geriatrics. 2018;18:24. doi: https:// doi.org/10.1186/s12877-018-0719-1

19. Luz Omaira GT, Leticia DS, Fabián CM. Evidence - and Betty Neuman's model - based nursing care to prevent delirium in the intensive care unit. Enfermeria Global. 2016 [cited 2019 Apr 17];(41):64-77. Available from: http://scielo.isciii. es/pdf/eg/v15n41/en_clinica4.pdf
20. Yang J, Zhou Y, Xu B, Wang P, et al. Risk factors of delirium in sequential sedation patients in intensive care units. BioMed Res Int. 2017:Article ID 3539872. doi: https://doi.org/10.1155/2017/3539872

\section{- Corresponding author:}

Alessandra Soler Bastos

E-mail: lekasoler@hotmail.com

Associate editors:

Aline Marques Acosta

Graziella Badin Aliti

Editor-in-chief:

Maria da Graça Oliveira Crossetti 